Revista Água Viva

\title{
IMIGRANTES E MASCATES DE B. KUCINSKI: UMA REFLEXÃO SOBRE A GRAVIDADE DOS PROBLEMAS DE MIGRAÇÃO E REFÚGIO NA ATUALIDADE
}

\author{
MMIGRANTS AND MASKERS OF B. KUCINSKI: A REFLECTION ON THE \\ GRAVITY OF MIGRATION AND REFUGE PROBLEMS NOW
}

\author{
Cíntia Schwantes ${ }^{1}$ \\ Graciane Cristina M. Celestino ${ }^{2}$ \\ Júlio Edstrom S. Santos ${ }^{3}$
}

Recebido em: 12 mai. 2020

Aceito em: 29 out. 2020

DOI: 10.26512/aguaviva.v5i3.35810

RESUMO: Este artigo procura demonstrar a relevância do tema dos migrantes forçados e refugiados, que é considerada a maior crise humanitária da atualidade, já que há mais de 65 milhões de pessoas vivendo em condições de extremo desamparo no mundo, através do diálogo com a obra literária infanto-juvenil Imigrantes e mascates de Bernardo Kucinski. Para tanto foi utilizado o método hipotético dedutivo e análise discursiva para apontar a seriedade da necessidade de proteção e promoção dos refugiados que chegam ao Brasil, através da integração dos fenômenos literários e jurídicos que servem de base para reflexões da própria sociedade brasileira.

Palavras chave: Imigrantes e mascates. Bernardo Kucinski. Migrantes forçados. Refugiados.

ABSTRACT: This paper attempts to demonstrate the relevance of the issue of forced migrants and refugees, which is considered the greatest humanitarian crisis today, since there are more than 65 million people living in conditions of extreme helplessness in the world, through the dialogue with the literary work: Immigrants and peddlers by Bernardo Kucinski. The hypothetical deductive method and discursive analysis were used to point out the seriousness

\footnotetext{
${ }^{1}$ Doutora em Letras pela Universidade Federal do Rio Grande do Sul/Indiana University (UFRGS). Mestra em Literatura pela Universidade de Brasília (UnB). Professora Adjunta da Graduação e do Pós Graduação em Literatura (UnB). Linhas de Pesquisa: Literatura e Autoritarismo; Representação na Literatura Contemporânea; e Estudos Literários Comparados. E-mail: ckschw@gmail.com

${ }^{2}$ Doutoranda em Literatura pela Universidade de Brasília (UnB). Licenciada em Letras (Português/Inglês) pela Universidade Estadual de Goiás (UEG). Mestra em Educação pela UnB. Professora Adjunta III, de Língua e Literatura de expressão Portuguesa e Inglesa no Centro Universitário Planalto do Distrito Federal (UNIPLAN). Email: graciane.celestino@docente.suafaculdade.com.br

3 Doutor em Direito pelo Centro Universitário de Brasília (UNICEUB). Mestre em Direito Internacional Econômico pela UCB/DF. Professor do IDASP-Palmas. Membro dos grupos de pesquisa Núcleo de Estudos e Pesquisas Avançadas do Terceiro Setor (NEPATS) da UCB/DF e Políticas Públicas e Juspositivismo, Jusmoralismo e Justiça Política do UNICEUB. E-mail: edstron@yahoo.com.br
} 
of the need to protect and promote refugees arriving in Brazil through the integration of literary and juridical phenomena that serve as a basis for Brazilian society's own reflection.

Keywords: Immigrants and peddlers. Bernardo Kucinski. Forced migrants. Refugees.

\section{INTRODUÇÃO}

A realidade de milhões de refugiados é um dos maiores problemas da atualidade, segundo dados das instituições ligadas a Organização das Nações Unidas. Assim, este esforço acadêmico busca chamar a atenção para essa situação, apontando dados oficiais de órgãos internos e internacionais sobre a situação dos refugiados. Destacamos, inclusive, o fato de que a condição de refúgio vem se agravando em todo o mundo, gerando repercussões em todos os países.

Neste sentido, alinhando uma visão da literatura, exposta pela obra Imigrantes $e$ mascates de Bernardo Kucinski e das instituições jurídicas, evidenciamos a necessidade de atuação contra circunstâncias aviltantes da própria condição humana. O texto em questão é o primeiro livro infanto-juvenil escrito pelo autor, apresentado como um relato memorialístico de suas experiências pessoais, quando com sua família veio para o Brasil.

Deste modo, este artigo busca abrir diálogos sobre as causas e efeitos do instituto do refúgio, sobretudo no Brasil. Alinhando a dimensão da literatura infanto-juvenil, afinal, é necessário que compreendamos quais as possibilidades de análise de textos como estes na Educação Básica, posto que se tornou um problema que tem atingido toda a humanidade na contemporaneidade.

\section{$2 \mathrm{O}$ direito à migração: necessidade constitucional e internacional de proteção aos refugiados no Brasil}

Infelizmente, não é exagero afirmar que a humanidade assiste, quase sem condições de apresentar uma resposta, a mais grave crise humanitária de sua história recente. Neste sentido, o Alto Comissariado das Nações Unidas para Refugiados (ACNUR), instituição criada pela Organização das Nações Unidas (ONU) após a Segunda Guerra Mundial para coordenar as respostas internacionais a esta situação, demonstrou que no ano de 2017, havia 68,5 milhões de pessoas em deslocamento forçado no mundo, ou seja, há um alto quantitativo de pessoas que 
não tem nenhuma proteção jurídica dentro ou fora dos países, sobrevivendo à parte de todo acolhimento da atual sociedade global. Reconhece-se que, atualmente, ainda se aplica aos refugiados a lição de Dalcastagnè: "Muitas Guerras e muitas crianças depois, chegamos ao final do século XX e à periferia do mundo, onde a necessidade de narrar o que não pode ser dito" (2018, p. 181).

Salientamos que o refúgio é um instituto humanitário, com raízes na antiguidade, que vem ganhando relevância desde o final da Segunda Guerra Mundial, na qual o planeta foi confrontado com milhões de pessoas que foram forçadas a deixar seus países, dado o temor por suas vidas e os perigos daquele conflito que levaram, inclusive, ao holocausto dos judeus, comunistas, ciganos e homossexuais na Alemanha e nos países que foram ocupados pelos nazista, levando-nos a uma constatação histórica empreendida por Hanna Arendt (2013) sobre as dificuldades dos refugiados a sua época:

É a mesma história em todo o mundo, repetidas vezes. Na Europa os nazis confiscaram a nossa propriedade; mas no Brasil tínhamos que pagar 30\% da nossa saúde, como a maioria dos membros leais do Bund der Auslandsdeutschen. Em Paris não podíamos sair das nossas casas depois das oito horas porque erámos judeus; mas em Los Angeles estávamos sob restrições porque erámos "inimigos aliados". A nossa identidade mudava tão frequentemente que ninguém conseguia descobrir quem erámos de facto (ARENDT, 2013, p. 13)

Em síntese, a situação de desamparo dos refugiados foi tão grave que ainda em 1951 houve a "Convenção Relativa ao Estatuto dos Refugiados", devido aos milhões de europeus, principalmente judeus, que haviam deixado seus países e forçadamente migraram para outros Estados, como o Brasil. Porém, aquele documento jurídico internacional não contemplava a situação das pessoas atingidas em outros continentes como a África e a Ásia. Assim foi negociado e ratificado pela sociedade internacional o "Protocolo de 1967 Relativo ao Estatuto dos Refugiados", gerando o dever internacional de reconhecimento e proteção às pessoas atingidas por aquele conflito.

A questão dos refugiados é tão relevante no contexto atual que no ano de 2018 foi assinado em Nova York o “Pacto Global sobre Refugiados e Migrantes” envolvendo 193 países, na busca por uma solução para este desafio mundial. Porém, já presenciamos uma fragmentação na história dos direitos humanos no Brasil, ou seja, apesar de sermos o maior país em extensão 
territorial da América Latina e com um passado de recebimento de fluxos migratórios, no ano de 2019, o Governo brasileiro ${ }^{4}$ manifestou seu interesse em deixar aquele acordo internacional, causando perplexidade na sociedade internacional.

É ainda necessário se reconhecer que as situações dos refugiados e dos migrantes forçados esbarram nas dificuldades de inserção e convivência com costumes e hábitos diferentes, tal como apontou Lindgren-Alves (2018), sendo assim gerada a necessidade diária de exercício da alteridade para se conviver com o que nos é estranho, com o fito de evitar atos de xenofobia que, não obstante, são praticados cotidianamente.

O tema da proteção dos refugiados se tornou tão singular para a sociedade internacional que foi reconhecido ao lado do Direito de Guerra e do Direito Humanitário, o Direito dos Refugiados, compondo a terceira vertente específica do que é chamado de "Direito Internacional dos Direitos Humanos". Ou seja, a positivação de um conjunto mínimo de proteção jurídica que todos os países devem ofertar às pessoas, independentemente de sua nacionalidade, simplesmente por sua condição de ser humano, tal como lecionaram Trindade, Peytrignet e Santiago (2003).

Também não se deve olvidar que ao lado do direito humano (internacional) e fundamental (interno) de liberdade de deslocamento, que em situações normais todas as pessoas podem escolher onde querem viver. Há, entretanto, condições tristes e especiais, em que os indivíduos têm que deixar as suas casas muitas vezes às pressas e sem a mínima condição de sobrevivência, dado o risco a sua vida e de seus familiares. Isso impõe o reconhecimento de que: "Estamos em uma fase decisiva, na qual o sucesso em gerenciar o deslocamento forçado global exige uma abordagem nova e muito mais abrangente, para que os países e as comunidades não lidem sozinhos com esse tema" (ACNUR, 2018, p. 2). Ou ainda, conforme a lição de Zygmunt Bauman (2017) sobre a necessidade atual de proteção aos refugiados de outros refugiados:

Para os indesejáveis que suspeitam ter chegado ao fundo do poço, a descoberta de outro fundo abaixo daquele em que eles próprios foram lançados é um evento de lavar a alma, que redime sua dignidade

\footnotetext{
${ }^{4}$ BBC News: Em comunicado a diplomatas, governo Bolsonaro confirma saída de pacto de migração da ONU. Disponível em: https://g1.globo.com/politica/noticia/2019/01/08/em-comunicado-a-diplomatas-governobolsonaro-confirma-saida-de-pacto-de-migracao-da-onu.ghtml
} 
humana e recupera o que tenha sobrado de autoestima (BAUMAN 2017, p. 18).

Assim, juridicamente a migração é um direito de todas as pessoas que escolhem livremente onde querem viver por questões pessoais ou profissionais. Neste diapasão, cada um deve ser incentivado a ir (emigrar) e vir (imigrar) para qualquer região, dentro ou fora dos atuais limites territoriais, conforme as atenhas legais, estabelecidas em cada país. Portanto, o fluxo populacional pode ocorrer espontaneamente ou ser forçado por questões ambientais, econômicas, políticas ou sociais, como a incidência de guerras. Um exemplo disso é o que ocorre na Síria, ou violência, como é experimentada na América Central, ou ainda conforme lição doutrinária:

Os motivos para a migração (internacional ou interna) são dos mais
variados, normalmente ligados a questões políticas, sociais, econômicas
ou ambientes. Também são variadas as razões das discriminações
sofridas, podendo ser citadas, $v . g$., a origem nacional, a idade, o gênero,
a orientação sexual, o pertencimento étnico racial e a situação de
extrema pobreza (MAZZUOLI, 2018, p. 409).

A vergonhosa realidade é que este número de migrantes forçados e refugiados não para de crescer exponencialmente, tal como aponta o gráfico do ACNUR a seguir: 


\section{Países que mais geraram refugiados em 2017*}

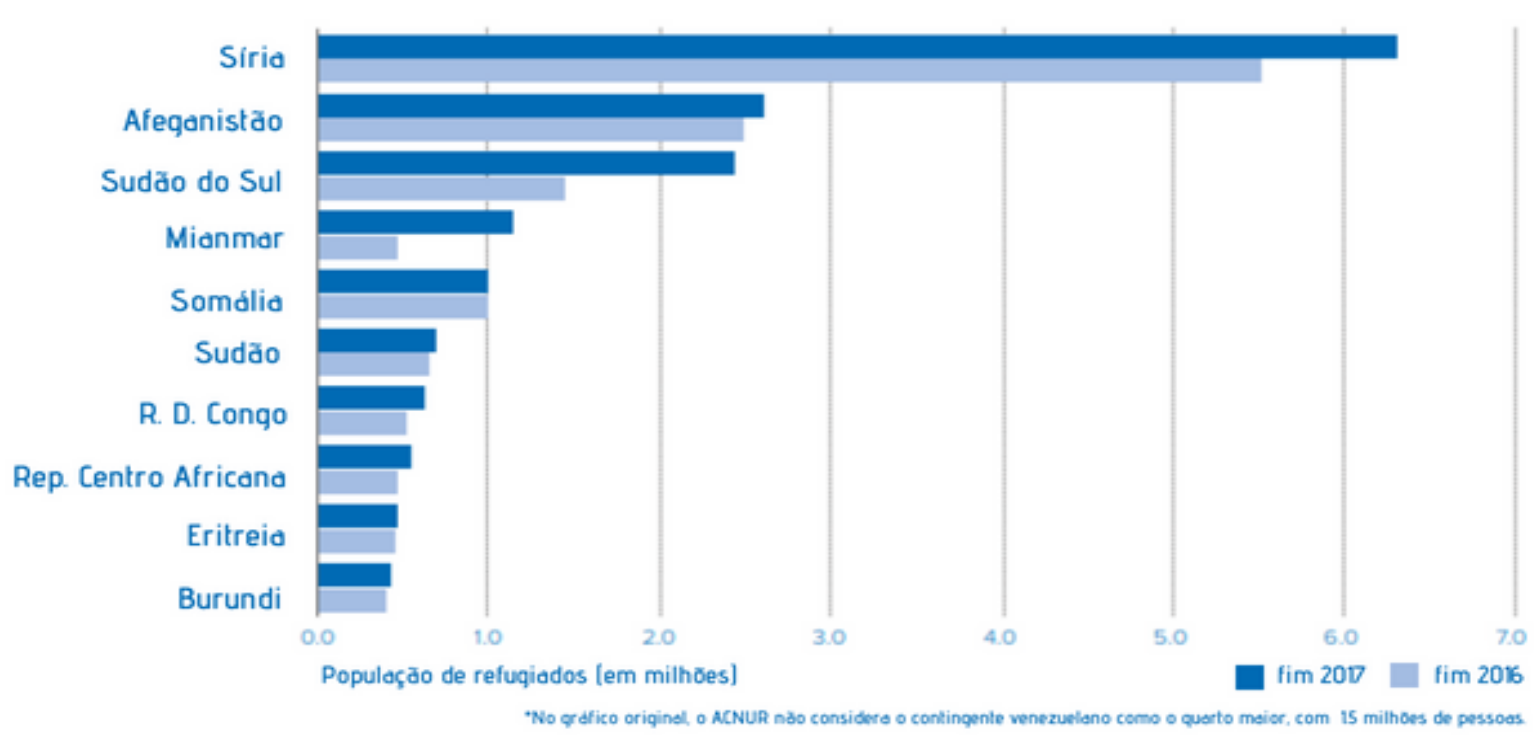

Destarte, o filósofo Giorgio Agamben (2015) apontou alguns dos problemas terminológicos e procedimentais que os refugiados vêm enfrentando na atualidade, sobretudo, com a perda da sua nacionalidade, que os torna apátridas, e neste sentido, sem nenhuma proteção estatal, da seguinte maneira:

Se o refugiado representa, no ordenamento do Estado-nação, um elemento tão inquietante, antes de tudo porque, rompendo a entidade entre homem e cidadão, entre natividade e nacionalidade, põe em crise a ficção originária da soberania. Exceções particulares a esse princípio, naturalmente, sempre existiram: a novidade do nosso tempo, que ameaça o Estado-nação nos seus próprios fundamentos, é que partes crescentes da humanidade não são mais representáveis no seu interior. Por isso, na medida em que se rompe a velha trindade Estado-naçãoterritório, o refugiado, essa figura aparentemente marginal, merece ser, pelo contrário, considerado como a figura central da nossa história política. É importante não esquecermos que os primeiros campos foram construídos na Europa como um espaço de controle para refugiados, e que a sucessão de campos de internamento - Campos de concentração - campos de extermínio representa uma filiação perfeitamente real (AGAMBEN, 2015, p. 29).

No Brasil, por exemplo, as pessoas que não são nacionais natos, ou seja, aqueles que não nasceram no território nacional (jus solis), ou tem algum liame familiar reconhecido 
constitucionalmente ${ }^{5}$ (jus sanguinis), podem escolher entre construir suas vidas em nosso país como estrangeiros ou brasileiros naturalizados, preenchidos os requisitos previstos na Constituição e também na nova Lei de Migração - 13.445 de maio de 2017 - que regulamentou a situação dos imigrantes que estão em nosso país.

Um ponto a ser ressalvado é que a Lei de Migração busca superar o vetusto pensamento de que o estrangeiro era um risco à nação, logo, deveria ser evitado, tal como ocorreu em nosso passado recente talhado pela chamada "doutrina da segurança nacional", que em síntese buscava a proteção do nacional contra a nocividade do que era estranho ou estrangeiro.

Neste sentido, tanto ao migrante quanto ao refugiado se devem garantir os direitos essenciais, como saúde, segurança e educação, inclusive, para que haja a sua inserção na sociedade brasileira, já que: "o refugiado, para não perder sua humanidade, necessita de integração na comunidade que o recebe" (NASCIMENTO, 2014, p. 57). Existe aqui um ponto de convergência, já que ao mesmo tempo em que a cultura nacional necessita ser preservada, podendo também ser acrescida pelos valores daqueles que escolhem morar em nosso país, ou que devem ser protegidos, devido a possibilidade de alguma perseguição infundada que há contra elas.

Um ponto que demonstra a interseção cultural está na obra literária: Imigrantes $e$ Mascates, de Bernardo Kucinski, que narrou as dificuldades sofridas por refugiados que vieram para o Brasil, desde a Segunda Guerra Mundial, apontando os problemas que precisaram ser solucionados para sua integração. A obra aponta também que geralmente o migrante se adapta e contribui para a melhoria da comunidade local.

Lembramos que a norma jurídica no Brasil impõe o reconhecimento entre brasileiros natos e naturalizados, se distinguindo apenas diferenciações pontuais, como a exclusividade da assunção aos brasileiros natos ao cargo de Presidente da República, sua linha sucessória e aos cargos de diplomata de carreira e oficial militar, situações que ainda são regidas pela doutrina da segurança nacional, que ao nosso sentir já não faz mais sentido em um mundo

\footnotetext{
${ }^{5}$ Art. 12. São brasileiros: I - natos: a) os nascidos na República Federativa do Brasil, ainda que de pais estrangeiros, desde que estes não estejam a serviço de seu país; b) os nascidos no estrangeiro, de pai brasileiro ou mãe brasileira, desde que qualquer deles esteja a serviço da República Federativa do Brasil;
} 
interconectado. De maneira exemplificativa, aquele que nasceu em território nacional tem mesmo maior sentimento patriota do que aquele que escolheu viver aqui?

Do ponto de vista jurídico a diferença entre o migrante e o refugiado é a obliteração da vontade pessoal e a necessidade humanitária de proteção de todas as pessoas. O refugiado é aquele que é perseguido por causa da sua cor, raça, gênero, credo, convicção política, ou mesmo, por uma grave e generalizada violação dos direitos humanos, tal como aponta o primeiro artigo da Lei Federal 9.474 de $1997^{6}$, que regulamenta os tratados e outros documentos internacionais que o Brasil assinou sobre este assunto.

No ano de 2017 foi elaborado nosso último censo sobre refugiados apresentando que naquele momento, em que não havia se intensificado a crise na Venezuela, o Brasil havia reconhecido pouco mais de 10 mil refugiados pelo Conselho Nacional para Refugiados (CONARE), segundo os dados oficiais, apresentados no gráfico colacionado abaixo:

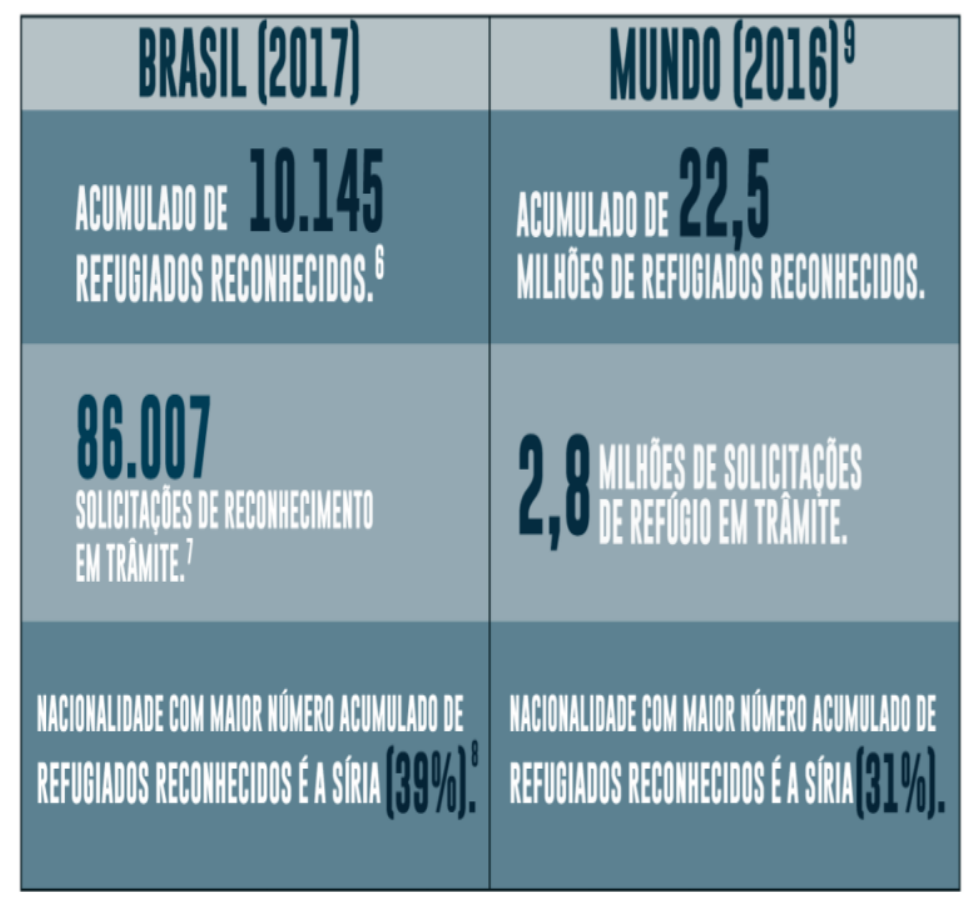

Conare/2018

\footnotetext{
${ }^{6}$ Lei Federal 9.474 de 1997Art. $1^{\circ}$ Será reconhecido como refugiado todo indivíduo que: I - devido a fundados temores de perseguição por motivos de raça, religião, nacionalidade, grupo social ou opiniões políticas encontrese fora de seu país de nacionalidade e não possa ou não queira acolher-se à proteção de tal país; II - não tendo nacionalidade e estando fora do país onde antes teve sua residência habitual, não possa ou não queira regressar a ele, em função das circunstâncias descritas no inciso anterior; III - devido a grave e generalizada violação de direitos humanos, é obrigado a deixar seu país de nacionalidade para buscar refúgio em outro país.
} 
Um ponto interessante é que pouco tempo após a publicação do último censo para refugiados, Calsing, Silva e Santos (2017), demonstraram academicamente que a proteção a estas pessoas ainda precisa ser aperfeiçoada, já que há fortes divergências interministeriais impedindo a cristalização dos direitos essenciais das pessoas em situação de migração forçada. Aparentemente não houve nenhuma melhoria frente a este problema.

Especificamente na América Latina, que é uma região em que devido à violência extrema e problemas ambientais, o número de migrantes forçados e também de refugiados não para de crescer, houve a adoção da Declaração de Cartagena no ano de 1984, que teve como um dos seus objetivos:

\footnotetext{
Ratificar a natureza pacífica, apolítica e exclusivamente humanitária da concessão de asilo ou do reconhecimento da condição de refugiado e sublinhar a importância do princípio internacionalmente aceite segundo o qual nada poderá ser interpretado como um ato inamistoso contra o país de origem dos refugiados (DECLARAÇÃO DE CARTAGENA 2019, p. 02).
}

Neste sentido, devido aos problemas internos, além da pressão internacional tensionada pelos acordos assinados, todos os países latino-americanos têm previsões constitucionais e legais para a proteção de asilados e refugiados, havendo a distinção apenas em nossa região de que o asilo é um instituto político e o refúgio uma proteção humanitária, tal como destacado anteriormente e apontado por Mazzuoli (2018).

\section{Imigrantes e mascates: memórias de infância}

Imigrantes e mascates é o título do primeiro livro de Bernardo Kucinski voltado para o público jovem. A obra comporta um relato acerca da invasão da Polônia pela Alemanha em 1939, quando o autor tinha apenas dois anos de idade, retratando sua infância, descoberta dos livros, influência de seu pai e as dificuldades que a família de origem judaica enfrentou. Todas essas memórias são relatadas de maneira a externar as experiências e incertezas de um dos períodos mais conturbados e violentos da história mundial.

O autor é jornalista e professor aposentado de jornalismo da Universidade de São Paulo, além de ter servido como assessor de comunicação da Presidência da República entre 2003 e 2005, escritor de obras de economia, política e jornalismo. Kucinski teve sua estreia na ficção 
marcada pelo livro K: Relato de uma busca, quando já contava com 74 anos. Seu livro mais recente é Cartas a Lula, em que reúne uma seleção de cartas escritas pelo então assessor da Presidência e entregues todos os dias às primeiras horas, lidas e discutidas pelo então presidente Luís Inácio, com seus assessores e ministros. Fome Zero, crise dos Correios, salário mínimo e o Mensalão são narrados nestas cartas, que tem, portanto, grande valor histórico.

Ao refletir acerca de qual tratamento teórico se daria ao texto em questão, Imigrantes $e$ mascates, optamos por analisar as relações entre linguagem e literatura. Atualmente, linguagem e literatura são entendidas como instâncias de interação no campo social, e mesmo de resistência a problemas sociais instalados. Para esse efeito, citamos Jouve (2012):

Se a arte não existe mais para os teóricos, ela ainda existe para a maioria dos individuo se, sobretudo, para uma série de instituições (ensino, imprensa, mídia) que pesam fortemente sobre nossa existência cotidiana. Assim, talvez não seja inútil de interrogar sobre uma "realidade" que, mesmo mal definida, "informa" - através de uma série de engrenagens - o mundo em que vivemos e nossa existência no interior deste mundo (JOUVE, 2012, p. 11).

Por conseguinte, ao se ler um texto que retrata a vida de um imigrante judeu que se vê obrigado, junto com sua família, a buscar um lar em um país que não é o seu, fica sempre o questionamento: para quê serve a literatura? Podemos entender a arte literária, bem como a linguagem em todas as dimensões dos saberes humanos, se perpetuarem como fundamentais para a constituição da cultura, educação e da relação entre os indivíduos, a interação. Quando escreveu o livro, B. Kucinski buscou, a nosso ver, proporcionar ao leitor a experiência de empatia, construção de identidade e reconhecimento da situação que vivem os milhões de migrantes e refugiados tal como descrito anteriormente.

O livro é dividido em relatos de sua infância, que se dão em ordem cronológica acentuada por uma narração vigorosa. A ordem é a seguinte: A primeira recordação; O meu bairro; O trenzinho da Cantareira; Nossa casa; A prima misteriosa; Bate-sola; Os chacareiros; As aulas de religião; As muitas vidas de meu pai; Religião e costumes; Os vendedores de rua; Os dez irmãos; A ocupação russa e a ocupação alemã; Prisão e fuga; Minha mãe; A descoberta dos livros; Nossa charrete; A guerra chega ao Brasil; Meu pai e a literatura; Minha primeira câmera; O desmonte; As mudanças; Meu primeiro choque; Um conto sobre si próprio. 
Desses relatos foram escolhidos dois, que mais adiante serão analisados detidamente. Neste sentido as experiências literárias são levadas a cabo por seu nível de interação com as estruturas que se apresentam no texto em questão. É importante observar que:

Parece haver um consenso quanto à importância das experiências de leitura, da sociabilização dessas leituras em diferentes contextos (inclusive, sobretudo, no contexto escolar) e do acesso aos acervos de obras literárias (principalmente nos anos em que se frenquenta o ensino básico) para a formação do leitor e de seus hábitos de leitura (REZENDE E JOVER-FALEIROS, 2013 p. 12)

A questão da estrutura discursiva e de compreensão entre as experiências literárias e a literatura, configuram-se em um procedimento de duas facetas, pois o ato de ler não se ensina, se vivencia, claro que estimulado, e sendo suscitada a atividade própria da criação e fruição estética, pois esses processos são necessários à devida compreensão (DALVI, REZENDE e JOVER-FALEIROS, 2013). O que em muitos dos relatos é perceptível na escrita de Kucinski. Neste sentido, as transformações nas experiências sociais, subjetivas e leitoras, encontram efetivação na medida em que sua consciência conduz o leitor à alteridade.

\subsection{A primeira recordação: relato de uma experiência}

Ao situar a vinda de sua família e suas primeiras recordações no bairro de Água Fria, em São Paulo, Kucinski desenvolve uma narrativa saudosista, em que conta com detalhes as peculiaridades de sua casa, atividades domésticas de sua mãe e sua impressão acerca da infância que vivenciava em trechos como:

A guerra afetou profundamente minha infância devido ao morticínio dos judeus pelos nazistas. Um episódio tão tenebroso da história que recebeu o nome de Holocausto, o mesmo dado pelos gregos a sacríficios de animais aos deuses, em que só restassem cinzas. Exatamente como os nazistas faziam com os corpos dos judeus assassinados (KUCINSKI, 2016 p. 07)

A possibilidade de habitar a melancolia com a qual sua mãe se apresentava tem profunda influência no menino Bernardo, pois sua memória instaura a recordação de dias que 
atormentaram nações e povos, por sua opressão e abusos. Petit (2009) observa que “ [...] a literatura ajuda a dar forma aos lugares onde viver, a se lançar e abrir caminho.” A analogia da condição dos judeus e da etimologia da palavra Holocausto remete ao total afastamento da experiência de empatia. Na frase: "[...] recebeu o nome de Holocausto, o mesmo dado pelos gregos a sacríficios de animais aos deuses, [...]" se evidencia um afastamento da condição humana que para Pètit é emanada da literatura.

Em outro trecho, também carregado de nostalgia, o autor indica qual teria sido o peso do Holocausto para ele, criança judia imigrante no Brasil:

Hoje, atribuo ao Holocausto as crises de melancolia de minha mãe, que nele perdeu seus pais, seus irmãos e quase todos os tios e primos. Também atribuo ao Holocausto o modo um tanto largado como vivíamos, sem disciplina nem organização. Era raro almoçarmos ou jantarmos juntos. Nossos sapatos nunca estavam engraxados e nossas roupas nunca estavam em ordem. Vez ou outra acontecia de eu não ter o que vestir para um desfile da escola ou uma festinha.

Igualmente, o autor apresenta os sentimentos dos emigrantes que assistiam chocados o que acontecia na Europa naquele momento. "Era como se meus pais estivessem aturdidos demais com o que acontecia na Polônia, ou, quem sabe, se contentassem com o simples fato de estarmos vivos." (KUCINSKI, 2016 p. 08)

A indefinição de sua situação em um país que suscita o estranhamento, ao mesmo tempo em que é nesse país que consegue vivenciar experiências sociais e pessoais, o relato sobre a maneira "largada", se referindo às questões de disciplina e organização domésticas, são formas como o narrador conduz o leitor de seu texto à empatia. Ademais, suscita uma reflexão acerca do que o filósofo Agamben (2014) chama de destruição da experiência na contemporaneidade conturbada em que a sociedade se encontra. Nesse sentido:

[...] para a destruição da experiência, uma catástrofe não é de modo algum necessária, e que a pacífica existência cotidiana em uma grande cidade é, para esse fim, perfeitamente suficiente. Pois o dia a dia do homem contemporâneo não contém quase nada que seja ainda traduzível em experiência: [...] (AGAMBEN, 2005, p. 22) 
Destarte, ao situar o real e sua não habitação na linguagem, a experiência na contemporaneidade, analisada por Agamben (2014) como uma destruição ou catástrofe que dimensionam a linguagem como articulada em sua materialidade, pode ser sentida no trecho em que o autor diz: “[...] Era como se meus pais estivessem aturdidos demais com o que acontecia na Polônia, ou, quem sabe, se contentassem com o simples fato de estarmos vivos" (2014, p. 48). Essa narrativa indica o papel da arte como ruptura em relação à vida, pois a linguagem transporta algo da subjetividade para o mundo real. Ao se deparar com a melancolia de sua mãe, Kucinski evidencia essa afirmativa ao relatar suas impressões da infância.

\subsection{As muitas vidas de meu pai: relato de uma descoberta}

O segundo dos relatos propostos para análise do livro de B. Kucinski, em que o autor faz referência à influência e admiração de Bernardo por seu pai, causa certa inquietude, pois compreende-se que a escrita literária parte de um ponto do real, atravessa a densidade linguística que lhe é peculiar e retorna de onde saiu, deixando um rasgo de experiências outras. Essa localização da escrita do presente relato se inicia com o subtítulo:"Meu pai iluminista“, em que o autor relembra como seu pai se tornou ferrenho adepto dos filósofos iluministas. $\mathrm{O}$ seguinte trecho, mais adiante, é intrigante:

Hoje, tudo o que se estuda na escola vem do saber científico. A geografia, a matemática, a biologia, enfim, tudo. Mas os meninos judeus daquela época ainda aprendiam a ler e a escrever numa escolinha religiosa chamada cheder, debruçados horas e horas sobre a Bíblia, a decorá-la. Por isso se revoltaram (KUCINSKI, 2016, p. 23).

Qualquer semelhança com a realidade é mera especulação, ou não. Nesse trecho podem ser percebidas tanto as significações relacionadas a uma obrigatoriedade que encaminha para a revolta, quanto uma variação no decurso temporal do signo e sua materialidade se instaura no momento da recognição mediada pelo deslocamento, que ocorre quando o autor narra em outro subtítulo do mesmo relato as atividades políticas de seu pai. Por conseguinte cremos que a verdade da literatura só pode ser pensada através da dinâmica do tempo em sua corporeidade. Quando a criança Bernardo recorda seu pai na narrativa o faz da seguinte forma: 


\begin{abstract}
Meu pai logo se desencantou com o Bund e ajudou a fundar um novo partido de trabalhadores, que além de socialista também fosse sionista. Ele convenceu-se de que os judeus precisavam sim de uma pátria, para estarem a salvo das perseguições, mas achava que essa pátria tinha que ser socialista, ou seja, um lugar onde todos ganhassem igual (KUCINSKI, 2016, p. 25).
\end{abstract}

O Bund era o partido de juventude do sindicato de trabalhadores judeus, que o pai de Kucinski ajudou a criar. Em iídiche, essa palavra significa "associação", contudo por conta de uma disputa interna entre sionistas e socialistas, ocorreu um processo de exclusão do pai, senhor Kucinski, que era socialista e se desiludiu com o partido. Ao correr da narrativa, é revelada a forma como ele descobre esses relatos, que foram escritos em um memorial por seu pai. Esse memorial foi descoberto décadas depois, quando da reunião comemorativa do partido, em que o autor encontrou na Universidade de Tel Aviv o manuscrito.

Mais adiante, em um terceiro subtítulo, o autor narra as atividades jornalísticas de seu pai. O que se percebe é que o literato quer de alguma forma forçar o espaço-tempo na escritura, deixando que a literatura situe e vivencie a incompletude de sentidos das representações parciais, a tensão política, o espaço da ficcionalidade, a apropriação memorialística, a trama do literário. Um exemplo dessa narrativa vigorosa é:

Chegando ao Brasil, meu pai continuou a escrever para dois jornais iídiches da Lituânia, um de Vilna, outro de Kovno. Depois que a Polônia foi invadida pela Alemanha, em setembro de 1939, dando início à Segunda Guerra Mundial, ele passou a escrever para os jornais iídiches de Nova York, Buenos Aires e os do Brasil, o Novo Momento e o Diário Israelita (KUCINSKI, 2016, p. 26).

O narrador ainda descreve o estilo de seu pai como sendo de ídiche erudito, ressaltando as abordagens polêmicas, e seu posicionamento duro contra as atitudes autoritárias alemãs, ao descrever como seu pai recebeu o fato de a Alemanha ter de indenizar o Estado de Israel, quando de sua proclamação em 1948. Ele conta que seu pai disse:"Nenhum dinheiro do mundo poderia pagar aquilo“ (KUCINSKI, 2016, p. 26).

As atrocidades e mortes, além dos milhares de judeus que imigraram ou buscaram refúgio em outros países tendo por finalidade sobreviver à guerra, eram razões suficientes para que o senhor Kucinski expressasse sua insatisfação com a situação em que se encontravam. 
A palavra soa como se tivesse conteúdo próprio ao ato de significar, seu caráter é hiperreflexivo e se sustenta na escritura como exílio. A linguagem atenta para o quanto a escrita é testemunha da história, do exílio, do tempo. Há neste sentido uma errância do indivíduo; a experiência judaica de ser alheio ao solo é como a experiência literária em relação à linguagem, que é um exílio que desfigura.

Nos subtítulos sequentes, Meu pai vendedor ambulante; Meu pai orador; Meu pai orador oficial; A vida se acomoda, há um amalgamento do texto enquanto tecido literário, quando relembra as experiências de seu pai como mascate, o autor realiza a figuração do acolhimento possível, ao narrar todas as circunstâncias que fizeram com que o comércio enquanto mascate fosse rentável para a família. Mais adiante, quando inicia as narrativas de seu pai como orador, as imagens textuais provocam reflexões. A ilustração do livro tem uma tendência à polifônia, além das fotografias antigas realizarem uma composição orgânica. O texto pode ser abordado como didático, até por seu caráter infanto-juvenil, no entanto ele comporta questões que suscitam discussões e debates críticos e éticos.

Ao denominar a maneira como a vida de sua família vai se acomodando financeiramente com a atividade de mascate desenvolvida por seu pai, o autor diz que:

\begin{abstract}
Aos poucos meu pai foi dando certo como mascate. Os ambulantes judeus vendiam com facilidade porque dividiam o pagamento em prestações mensais. Foram os inventores do crediário. Os antigos mascates sírios não podiam vender em prestações porque às vezes demorava mais de ano para passarem de novo no mesmo lugarejo. Nas cidades, era possível cobrar o freguês uma vez por mês. Depois de crescido eu mesmo percorri as quebradas da Cantareira cobrando os fregueses de meu pai (KUCINSKI, 2016, p. 32).
\end{abstract}

A relação entre experiência e memória no texto de Kucinski (2016) é de tal maneira associada às construções da imaginação que ao relatar como fazia para realizar a cobrança dos fregueses de seu pai, ele provoca curiosidade e motivação. Nesse sentido a mediação de uma leitura que parta das experiências culturais diversas, exercício da memória, leitura de clássicos, se constituem em prolongamentos de sentido e causa. As figuras de leitura que se desdobram na ficção de cada escritor são modeladas, assim como afirma Agamben (2005):

Porque tem o seu necessário correlato não no conhecimento, mas na autoridade, ou seja, na palavra e no conto, e hoje ninguém mais parece 
dispor de autoridade suficiente para garantir uma experiência, e se dela dispõe, nem ao menos o aflora a ideia de fundamentar em uma experiência a própria autoridade (AGAMBEN 2005, p. 23).

Ao escolher um texto de literatura infanto-juvenil para análise crítica, levamos em consideração alguns dados estatísticos, inclusive a utilização do próprio livro em aulas direcionadas a adolescentes e jovens, pois sentimos a necessidade de comprovar os dados relacionados ao desempenho dos alunos na escola. De acordo com a medição realizada pelo PISA (Programme for International Student Assessment), 54\% dos alunos com 15 anos estão abaixo do nível de leitura estimado. Já o SAEB (Sistema de Avaliação da Educação Básica) traz demonstrativos de mais de $60 \%$ das crianças que estão no quinto ano da Educação Básica (ROITMAN e RAMOS, 2011). Esses jovens ainda não atingiram níveis mínimos de leitura. O número de alunos vem aumentando bastante nos últimos vinte anos, contudo, menos de $60 \%$ dos jovens que ingressam no ensino médio conseguem terminar esse nível de ensino, e ainda há uma parcela bem menor que ingressa no ensino superior, demonstrando que apesar da melhoria no direito ao acesso à educação, ainda há muito o que se fazer nos processos de ensino e aprendizagem no Brasil.

No ano de 2007, foi criado o Índice de Desenvolvimento da Educação Básica (IDEB), que se tornou parte do Plano de Desenvolvimento da Educação (PDE), onde seriam previstas metas até 2021. O IDEB é medido a partir da Prova Brasil, aferida tendo por base as turmas de $5^{\circ}$ e $9^{\circ}$ anos, pois as avaliações citadas devem fazer com que o país atinja em 2021, a meta de 5,5. Essa prova é aferida em anos ímpares; 2019 foi um deles.

O fenômeno leitor em que o sujeito é formado por várias culturas é denominado de construção identitária singular. Ressalta-se que as leituras literárias nem sempre conseguem conviver em harmonia, pois elas são contraditórias. O que o jovem lê na escola, em muitos casos, não é o que o constitui enquanto leitor social de uma realidade e vivência de mundo (DALVI, REZENDE e JOVER-FALEIROS, 2013).

Os dados do Indicador do Alfabetismo Funcional (INAF) de 2011-2012 demonstram que $27 \%$ dos brasileiros com 15 anos ou mais, são analfabetos funcionais, $47 \%$ da população apresenta nível básico de alfabetização, 35\% das pessoas que concluíram o ensino médio estão plenamente alfabetizados e $38 \%$ dos jovens do ensino superior dominam e exercitam a leitura e a escrita, dados esses disponibilizados pelo Instituto Paulo Montenegro. 
É conveniente uma afirmação de subjetividade no ato da leitura, contudo é preciso evitar que os jovens obtenham uma subjetividade imoderada, o que poderia dar ensejo a processos de interpretação ilimitados e sem fundamentos. Nesse intuito, foi elaborado um plano de trabalho que tem por objetivo analisar o texto de Kucinski, por meio da mediação do professor de Projeto de Leitura, Produção Textual e Literatura, trabalho este que se encontra em fase de desenvolvimento em uma escola de Educação Básica do estado de Goiás, no município de Santo Antônio do Descoberto, entorno do Distrito Federal. A escolha se justifica pela necessidade em se tratar da temática da imigração, além de referendar a questão da narrativa memorialística.

Uma das questões que foram analisadas para tal elaboração se relaciona com a aproximação entre o texto de Kucinski, suas experiências e vivências de infância e a preparação do leitor jovem para a compreensão da diversidade. As narrativas do livro em questão geram empatia no jovem, pois o autor ao narrar suas experiências faz relações com as lembranças da escola, família e influência de seu pai nos estudos, que mais tarde vão formar sua autonomia e identidade enquanto leitor, jornalista e professor.

\section{CONSIDERAÇÕES FINAIS}

A pesquisa e análise do presente texto teve por finalidade oferecer uma modesta colaboração, afinal as considerações são sugestivas, para que possam ser discutidos livros de literatura infanto-juvenil que retratem debates e discussões acerca de temas contemporâneos em sociedade. Reconhecemos a necessidade da leitura de literatura para os jovens leitores, e que coexiste uma aproximação com a realidade social, consideramos que as aprendizagens vivenciadas pelos jovens em sua relação com a contemporaneidade precisam ser ressignificadas para que eles possam constituir-se enquanto seres humanos dotados de alteridade.

Assim, iniciamos por uma contextualização jurídica sobre a relevância do tema dos refugiados e da migração forçada no contexto nacional e internacional. Apontamos sinteticamente que após os horrores da Segunda Guerra Mundial houve um esforço da sociedade internacional em elaborar documentos internacionais em proteção aos milhões de desamparados.

Também apontamos que para além do direito humano e fundamental de migração, há uma diferença conceitual entre a pessoa que é obrigada a deixar sua moradia, sendo considerada 
um migrante forçado e aquele indivíduo que é perseguido por sua raça, credo ou convicção política pelas autoridades do seu próprio país e assim se torna um refugiado.

Demonstramos que os principais indicadores internacionais apontam que o número de migrantes forçados e refugiados já ultrapassou a casa dos 65 milhões, sendo considerada a mais grave crise humanitária da atualidade. Além do que, esta situação não está sendo mitigada. Destarte, o tema da proteção dos migrantes forçados e refugiados não é novo, mas é muito necessário já que cotidianamente são recebidas pessoas que precisam da proteção estatal e de inserção social, o que só pode ser atingido através do reconhecimento de sua relevância do ponto de vista jurídico, literário e social.

O estudo dos elementos literários e filosóficos, como alteridade, memória e experiência leitora, no livro Imigrantes e Mascates, em relação com a análise jurídica da condição do imigrante, evidenciaram características literárias e jurídicas que podem ser temáticas para se trabalhar com esse livro.

Nessa concepção utilizamos a mediação literária, além da concepção de leitura literária. Foram analisados dois capítulos do livro, que se dividiam em subtítulos. Após a análise dos dados de pesquisas nacionais e análise do texto literário em contrapartida refletimos sobre a capacidade de interiorização que a narrativa reitera sobre o leitor. A compreensão do ato da leitura como instância fundadora da escritura e a construção do espaço literário, sob uma visão de trânsito entre culturas diversas, são os pontos precípuos do trabalho apresentado.

\section{REFERÊNCIAS}

AGAMBEN, Giorgio. Infância e história: destruição da experiência e origem da história; tradução de Henrique Burigo. - Belo Horizonte: Editora da UFMG, 2005.

AGAMBEN, Giorgio. Meios sem os fins: Nota sobre politica. São Paulo: Autêntica, 2016.

ARENDT, Hannah. Nós, os Refugiados. Covilhã: Universidade da Beira Interior, 2013

BAUMAN, Zygmnunt. Estanhos à nossa Porta. Rio de Janeiro: Zahar, 2017.

BRASIL. Ministério da Educação. Secretaria de Educação Básica. Secretaria de Educação Continuada, Alfabetização, Diversidade e Inclusão. Secretaria de Educação Profissional e Tecnológica. Conselho Nacional de Educação. Câmara de Educação Básica. - Brasília: MEC, SEB,DICEI, 2013. 
CALSING, Renata de Assis; SILVA, Viviane Luiza; SANTOS, Júlio Edstron Secundino. Refugiados no Brasil: Estamos preparados para a proteção humanitária dessas pessoas? In Revista do Programa de Pós-Graduação em Direito da UFC v. 37.2, jul./dez. 2017

DALVI, Maria Amélia; REZENDE, Neide Luzia; JOVER-FALEIROS, Rita (Orgs.). Leitura de literatura na escola. São Paulo: Parábola, 2013.

DALCASTAGNE, Regina; LICCARIÃO, Berttoni; NAKAGOME, Patricia. Literatura e Resistência. Porto Alegre: ZOUK, 2018.

DALCASTAGNE, Regina; DUTRA, Paula Q.; FREDERIDO, Graziele. Literatura e Direitos Humanos. Porto Alegre: ZOUK, 2018.

INSTITUTO PAULO MONTENEGRO. Indicador de Analfabetismo Funcional - INAF: estudo especial sobre alfabetismo e mundo do trabalho. São Paulo: Instituto Paulo Monenegro, 2016. Disponível em: <http://acaoeducativa.org.br/wp-content/uploads/2016/09/ INAFEstudosEspeciais_2016_Letramento_e_Mundo_do_Trabalho.pdf >. Acesso em: 21 mar. 2017.

INSTITUTO PRÓ-LIVRO. Retratos da leitura no Brasil. 4. ed. São Paulo: Instituto PróLivro, 2016. Disponível em: <http://prolivro.org.br/home/images/2016/ Pesquisa_ Retratos_da_Leitura_no_Brasil_-_2015.pdf>. Acesso em: 21 mar. 2017.

JOUVE, Vincent. Por que estudar literatura? São Paulo: Parábola, 2012.

KUCINSKI, Bernardo. Imigrantes e mascates; ilustrações de Maria Eugênia. - $1^{\text {a }}$ ed. São Paulo: Companhia das Letrinhas, 2016.

LINDGREN-ALVES, José Augusto. É preciso salvar os direitos humanos! São Paulo: Perpsctiva, 2018.

MAZZUOLI, Valério de Oliveira. Curso de Direitos Humanos, 5 ed. São Paulo: Editora Método, 2018.

NASCIMENTO, Luiz Sales do. A cidadania dos refugiados no Brasil. 2 ed. São Paulo: Verbatim, 2014.

OLINTO, Heidrun Krieger; SCHOLLHAMMER, Karl Erik (orgs). Literatura e Cultura. Rio de Janeiro. Ed: PUC-Rio; São Paulo: Loyola, 2003.

ORGANIZAÇÃO DOS ESTADOS AMERIANOS (OEA) Declaração de Cartagena.

Disponível em:

https://www.acnur.org/fileadmin/Documentos/portugues/BD_Legal/Instrumentos_Internacion ais/Declaracao_de_Cartagena.pdf acesso em 10 janeiro 2019

PETIT, Michèle. A arte de ler ou como resistir à adversidade; tradução de Arthur Bueno e Camila Boldrini - São Paulo: Ed. 34, 2009

ROITMAN, Isaac e RAMOS, Neves Mozart. A Urgência da Educação. São Paulo: Moderna,2011. 
TRINDADE, Antônio Augusto Cançado; PEYTRIGNET, Gierard; SANTIAGO, Jaime Raiz. Las Tres Vertientes de La Protección Internacional de los derechos de la persona humana: derechos humanos, derechos humanitário, derecho de los refugiados. Ciudad del México: Editorial Porrua México, 2003. 